\title{
Caracterização físico-química de méis de Apis mellifera $L$ L. da região noroeste do Estado do Rio Grande do Sul
}

\author{
Physicochemical characterization of Apis mellifera L. honeys from the northwest region of \\ Rio Grande do Sul State
}

\author{
Juliane Elisa Welke ${ }^{\mathrm{I}}$ Sabrina Reginatto ${ }^{\mathrm{II}}$ Débora Ferreira' ${ }^{\mathrm{II}}$ Raul Vicenzi ${ }^{\mathrm{II}}$ José $_{\text {Maria }}$ Soares ${ }^{\mathrm{II}}$
}

\section{RESUMO}

O objetivo deste trabalho foi determinar a composição físico-química de méis de Apis mellifera L. produzidos em dois anos consecutivos na região noroeste do Estado do Rio Grande do Sul, Brasil. As características físicoquímicas de 36 amostras de mel foram comparadas utilizando o teste $T$ de Student e a adequação aos padrões da legislação brasileira da qualidade do mel foi verificada. Os resultados das análises dos méis variaram para as características analisadas conforme segue: $p H(3,3-4,4)$, umidade $(14,7-$ $19,8 \%$ ), acidez total (16,9-49,2meq $\left.\mathrm{kg}^{-1}\right)$, hidroximetilfurfural (0,15-48,3mg kg-1), açúcares redutores (60,1-75,9\%), açúcares não-redutores (1,35-5,99\%), cinzas (0,05-0,47\%) e sólidos insolúveis $\left(0,016-0,27 \mathrm{~g} \mathrm{~kg}^{-1}\right)$. A análise estatística das amostras de mel produzidas em dois anos consecutivos mostrou que houve diferença significativa na umidade, na acidez e na hidroximetilfurfural. Os méis produzidos nesta região apresentam boa qualidade e características físico-químicas compatíveis aos padrões da legislação brasileira.

Palavras-chave: apicultura, mel de abelhas, caracterização físico-química.

\section{ABSTRACT}

The objective of this research was to determine the physicochemical composition of Apis mellifera L. honeys produced in two consecutive years in the northwest region of Rio Grande do Sul State, Brazil. The physicochemical characteristics of 36 honey samples were compared using Student's T-test and their adequacy to standards established by the Brazilian legislation for honey quality was checked. The results varied as follows: $p H$ (3.3-4.4), moisture (14.7-19.8\%), acidity (16.9-49.2meq $\left.\mathrm{kg}^{-1}\right)$, hydroxymethylfurfural content (0.15-48.3 mg kg-1), reducing sugar (60.1-75.9\%), nonreducing sugar (1.35-5.99\%), ashes (0.05-0.47\%) and solids non-soluble in water $\left(0.016-0.27 \mathrm{~g} \mathrm{~kg}^{-1}\right)$. The statistical analyses of honey samples produced in two consecutive years showed that the moisture, acidity and hydroxymethylfurfural content varied significantly. The honey samples produced in this region were in accordance with the Brazilian legislation for honey quality.

Key words: apiculture, bee honey, physicochemical characterization.

\section{INTRODUÇÃO}

A criação de abelhas constitui-se em uma atividade em que se consegue obter bons resultados econômicos e vem despertando interesse de muitos criadores e várias instituições do Brasil (EVANGELISTARODRIGUES et al., 2005). Quimicamente o mel é composto por açúcares (70-80\%), com predominância de glicose e frutose, água (10-20\%) e outros constituintes em proporções mínimas como sais minerais, ácidos orgânicos, vitaminas, compostos fenólicos, proteínas e aminoácidos livres (TERRAB et al., 2001).

A legislação brasileira define mel como produto alimentício produzido pelas abelhas melíferas, a partir do néctar das flores ou das secreções procedentes de partes vivas das plantas ou de secreções de insetos sugadores de plantas que ficam sobre partes vivas de plantas, que as abelhas recolhem, transformam, combinam com substâncias específicas próprias, armazenam e deixam madurar nos favos da colméia (BRASIL, 2000).

\footnotetext{
IUniversidade Regional do Noroeste do Estado do Rio Grande do Sul (UNIJUÍ), 98900-000, Santa Rosa, RS, Brasil. E-mail: juliane_welke@yahoo.com.br. Autor para correspondência.

IIDepartamento de Biologia e Química, UNIJUÍ, Santa Rosa, RS, Brasil.
} 
É comum encontrar no mel variações na sua composição física e química, tendo em vista que vários fatores interferem na sua qualidade, tais como condições climáticas, estágio de maturação, espécies de abelhas e tipo de florada (PÉREZ et al., 2007), como também o processamento e o armazenamento deste produto (AZEREDO et al., 2003). Entretanto, ele não poderá ter açúcares e/ou outras substâncias que alterem sua composição (BRASIL, 2000).

A obtenção de parâmetros físico-químicos de méis é importante para sua caracterização (SERRANO et al., 2004), como também é primordial para garantir a qualidade desse produto no mercado. Além disso, é de fundamental importância a caracterização regional de méis, levando-se em consideração a grande diversidade botânica e a variação climática de cada região (TERRAB et al., 2001).

O presente trabalho objetivou determinar a composição físico-química de méis de Apis mellifera produzidos em dois anos consecutivos na região noroeste do Estado do Rio Grande do Sul, visando comparar as características entre os dois anos e também verificar a adequação do méis aos padrões da legislação brasileira da qualidade do mel.

\section{MATERIAL E MÉTODOS}

A pesquisa foi realizada no Laboratório de Química da Universidade Regional do Noroeste do Estado do Rio Grande do Sul, Santa Rosa, RS. Trinta e seis amostras de mel provenientes dos municípios da região noroeste do Estado do Rio Grande do Sul foram adquiridas na Feira de Apicultores, realizada no mês de dezembro de 2005 e 2006, na cidade de Santa Rosa, RS, sendo 18 amostras do ano de 2005 e 18 amostras de 2006, coletadas dos mesmos apicultores em ambos os períodos. As amostras encontravam-se envasadas em frascos de plásticos e mantidas à temperatura ambiente, sendo analisadas em triplicata, no máximo um mês após a colheita.

As análises dos parâmetros correspondentes às características físico-químicas de mel recomendados pelo Ministério da Agricultura e Abastecimento (BRASIL, 2000) foram realizadas segundo metodologia oficial desta Instrução Normativa.

A determinação do $\mathrm{pH}$ foi realizada de acordo com as Normas Analíticas do Instituto Adolfo Lutz (1985) com pHmetro digital marca Procyon, pH 10.

A umidade foi determinada por refratometria, segundo método no 969.38b (AOAC, 1998). O princípio deste método baseia-se na determinação do índice de refração do mel a $20^{\circ} \mathrm{C}$, sendo que para cada grau acima da temperatura que a amostra apresentou acrescentou- se 0,00023 . O índice de refração corrigido foi convertido para percentagem de umidade por meio de uma tabela de referência.

A acidez total de méis é conseguida por meio da determinação da acidez livre e lactônica e foi determinada de acordo com o método no 962.19 da AOAC (1998), em que para a acidez livre titulou-se a amostra com solução de $\mathrm{NaOH} 0,05 \mathrm{~N}$, até atingir o pH 8,5. Para a acidez lactônica, após a solução alcançar o $\mathrm{pH}$ de 8,5, foram pipetados $10 \mathrm{~mL}$ de $\mathrm{NaOH} 0,05 \mathrm{~N}$ e com $\mathrm{HCl}$ 0,05N fez-se uma titulação de retorno até $\mathrm{pH}$ 8,3 .

O conteúdo de hidroximetilfurfural (HMF) foi determinado por meio do método espectrofotométrico a 284 e 336nm, conforme método no 980.23 (AOAC, 1998).

A determinação de açúcares redutores foi feita segundo o método do CAC (1990) a partir da modificação do procedimento de Lane e Eynon, envolvendo a redução da solução de Fehling, modificado por Soxhlet, durante a titulação no ponto de ebulição com uma solução de açúcares redutores do mel, usando azul de metileno como indicador. $\mathrm{O}$ conteúdo de sacarose aparente foi determinado após a inversão por hidrólise ácida, segundo método do CAC (1990).

O teor de cinzas foi determinado por meio da incineração das amostras em mufla a $600^{\circ} \mathrm{C}$ até um peso constante (CAC, 1990). A determinação do teor de sólidos insolúveis em água foi feita por gravimetria, segundo o método do CAC (1990).

Com o objetivo de verificar as diferenças de cada característica físico-química das amostras de mel dos mesmos apicultores nas floradas de dois anos consecutivos, os dados foram tratados estatisticamente aplicando-se o teste $\mathrm{T}$ de Student com intervalo de confiança de $95 \%$.

\section{RESULTADOS E DISCUSSÃO}

O mel é naturalmente ácido, sendo que seu pH está entre 3,3 e 4,4 (Tabela 1). Os valores observados estão dentro da faixa de $\mathrm{pH}$ obtida por MARCHINI et al. (2005), que foi de 2,9 a 5,1 para méis de eucalipto do Estado de São Paulo. Já EVANGELISTA-RODRIGUES et al. (2005), em análise de méis na Paraíba, demonstraram uma variação de 3,8 a 4,7 no pH das amostras analisadas.

Embora o pH não seja indicado, atualmente, como análise obrigatória no controle de qualidade dos méis brasileiros, mostra-se útil como variável auxiliar para avaliação da qualidade, pois é um parâmetro de importância na extração e no armazenamento do mel 
Tabela 1 - Valores estabelecidos pela legislação brasileira para mel de abelhas, valores médios, desvios-padrão e intervalos de variação do $\mathrm{pH}$, umidade, acidez total, HMF, açúcares redutores, açúcares não-redutores, cinzas e sólidos insolúveis em água para as amostras de mel analisadas

\begin{tabular}{|c|c|c|c|c|c|}
\hline \multirow[b]{2}{*}{ Parâmetro } & \multirow[b]{2}{*}{ Norma vigente* } & \multicolumn{2}{|c|}{--------Méis florada 2005-------- } & \multicolumn{2}{|c|}{--------Méis florada 2006-------- } \\
\hline & & Média $\pm \mathrm{s}(\mathrm{m})^{* *}$ & Variação & Média $\pm \mathrm{s}(\mathrm{m})^{* *}$ & Variação \\
\hline $\mathrm{pH}$ & ---------- & $4,0 \pm 0,2$ & $3,7-4,4$ & $3,8 \pm 0,1$ & $3,3-4,2$ \\
\hline Umidade (\%) & Máximo 20 & $16,2 \pm 0,09$ & $14,7-18,1$ & $18,5 \pm 0,01$ & $16,6-19,8$ \\
\hline Acidez total (meq kg-1) & Máximo 50 & $30,1 \pm 9,2$ & $16,9-49,3$ & $39,8 \pm 7,7$ & $26-49,2$ \\
\hline $\operatorname{HMF}\left(\mathrm{mg} \mathrm{kg}^{-1}\right)$ & Máximo 60 & $4,7 \pm 10,5$ & $0,15-46,3$ & $8,5 \pm 10,6$ & $0,15-48,3$ \\
\hline Açúcares & Mínimo 65 & $67,8 \pm 0,03$ & $60,1-75,9$ & $67,1 \pm 0,03$ & $65,0-71,9$ \\
\hline \multicolumn{6}{|l|}{ Redutores (\%) } \\
\hline Açúcares não-redutores (\%) & Máximo 6 & $4,29 \pm 0,01$ & $1,35-5,99$ & $3,57 \pm 0,01$ & $1,46-5,99$ \\
\hline Cinzas (\%) & Máximo 0,6 & $0,23 \pm 0,001$ & $0,05-0,47$ & $0,19 \pm 0,001$ & $0,05-0,4$ \\
\hline Sólidos Insolúveis (g kg-1) & Máximo 1 & $0,13 \pm 0,001$ & $0,016-0,24$ & $0,12 \pm 0,001$ & $0,04-0,27$ \\
\hline
\end{tabular}

*(BRASIL, 2000)

** Desvio-padrão da Média.

(CORBELLA \& COZZOLINO, 2006). OpH influenciana textura, na estabilidade e na vida de prateleira do mel, visto que valores alterados de $\mathrm{pH}$ podem indicar fermentação ou adulteração do mel de abelhas (TERRAB et al., 2004).

Pelos resultados obtidos para umidade das amostras de méis analisadas (Tabela 1), observa-se que esses valores se encontram abaixo do limite máximo permitido pela legislação vigente de $20 \%$, estabelecido pelo Ministério da Agricultura, Pecuária e Abastecimento (BRASIL, 2000). O valor de umidade encontrado está abaixo do valor médio de $18,91 \%$, encontrado por MARCHINI et al. (2004) em análise de méis de Apis mellifera do Estado do Tocantins, e de MARCHINI et al. (2005), que encontraram valor médio de 19,1\% para mel silvestre e de $21,2 \%$ para mel de eucalipto.

Os valores de umidade observados nesse estudo variaram de 14,7 a 19,8\%, sendo considerados adequados para assegurar a ausência de fermentação. A umidade pode ser influenciada pela origem botânica da planta, por condições climáticas e geográficas ou pela colheita do mel antes de sua completa maturidade (NANDA et al., 2003). Ela é uma das características mais importantes, pois pode influenciar na viscosidade, peso específico, na maturidade, na cristalização, no sabor e na conservação do mel (TERRAB et al., 2003), visto que microrganismos osmófilos podem provocar a fermentação do mel quando a umidade for muito elevada (GLEITER et al., 2006).

Os valores de acidez dos méis analisados (Tabela 1) estão dentro dos padrões de qualidade recomendados pela legislação, que determina um limite máximo de 50meq $\mathrm{kg}^{-1}$ demel(BRASIL, 2000). Em estudos prévios, MARCHINI et al. (2005) encontraram valores médios semelhantes de acidez, de 33,8meq $\mathrm{kg}^{-1}$, e AZEREDO et al. (2003) encontraram o valor 34,3meq $\mathrm{kg}^{-1}$.

O mesmo observado para os valores de umidade pode ser considerado para os valores de acidez encontrados neste estudo, pois a acidez dos méis analisados (abaixo de $50 \mathrm{meq} \mathrm{kg}^{-1}$ ) indica a ausência de fermentação, qualificando assim as amostras estudadas. A acidez do mel deve-se a diversos fatores: a variação dos ácidos orgânicos causada pelas diversas fontes de néctar, a atividade enzimática da glicoseoxidase que origina o ácido glucônico, a ação das bactérias durante a maturação e os minerais presentes em sua composição que influenciam a textura e a estabilidade do mel (TERRAB, 2003).

Os índices de hidroximetilfurfural dos méis analisados (Tabela 1) se enquadraram nos padrões exigidos pela legislação brasileira vigente, que estabelece um valor máximo de $60 \mathrm{mg} \mathrm{kg}^{-1}$ (BRASIL, 2000). O intervalo de variação apresentado nas floradas de 2005 e 2006 foi superior ao intervalo de 24,2 a 38,8mg $\mathrm{kg}^{-1}$ encontrado por TERRAB et al. (2003), que analisaram méis da Espanha. Os valores encontrados no presente estudo se apresentaram próximos aos valores de SILVA et al. (2004) em análise de méis do Piauí para diferentes floradas, 4,33 e 8,96 $\mathrm{mg} \mathrm{kg}^{-1}$ para mel silvestre e da florada de jitirana (Ipomoea sp.) respectivamente.

Os valores de HMF indicam que os méis analisados eram frescos, não adulterados e não haviam sido submetidos a períodos prolongados de armazenamento. O HMF é utilizado como indicador de qualidade, uma vez que tem origem na degradação de enzimas presentes nos méis e apenas uma pequena quantidade de enzima é encontrada em méis maduros e recém-colhidos (TERRAB et al., 2001), enquanto que 
valores mais elevados podem indicar alterações provocadas por armazenamento prolongado em temperatura ambiente e/ou superaquecimento ou adulterações provocadas pela adição de açúcar (AZEREDO et al., 2003).

Pelos resultados (Tabela 1), observa-se que todas amostras apresentaram valores para açúcares redutores acima do valor mínimo de $65 \%$ estabelecido pelo Ministério da Agricultura, Pecuária e Abastecimento (BRASIL, 2000). Do mesmo modo, verifica-se que as amostras enquadravam-se no valor máximo de 6\% para açúcares não-redutores, expressos em sacarose, conforme estabelecido pela legislação brasileira vigente (BRASIL, 2000). Os resultados das análises de açúcares deste trabalho são semelhantes aos resultados apresentados por AZEREDO et al. (2003), que analisaram méis comercializados em vários estados do Brasil e encontraram variação de 38 a 73,5\% para açúcares redutores e de 3,5 a 5,4\% para açúcares não redutores. SILVA et al. (2004) encontraram variação maior, de 68,92 a 85,49\%, nos valores de açúcares redutores em méis e para açúcares não redutores de 1,57 a $3,07 \%$.

Os resultados obtidos no presente estudo confirmam que os açúcares representam os maiores constituintes do mel, sendo a frutose e a glicose os maiores açúcares presentes. A glicose determina a tendência de cristalização do mel devido a sua pouca solubilidade, enquanto que a frutose tem alta higroscopicidade e favorece a doçura do mel (GLEITER et al., 2006). Já altos valores de sacarose, que se constitui da combinação destes dois açúcares, glicose e frutose, indicam que o mel foi colhido antes do período ideal, sendo que a sacarose não foi completamente transformada em glicose e frutose pela ação da invertase (AZEREDO et al., 2003). Valores altos de sacarose também podem indicar adulteração pela adição deste açúcar.

O conteúdo de cinzas das amostras variou de 0,05 a $0,47 \%$. Estes valores (Tabela 1 ) encontravamse de acordo com os padrões estabelecidos pela legislação brasileira para méis de abelhas, que admite um valor máximo de 0,6\% (BRASIL, 2000), o que qualifica as amostras analisadas. O conteúdo médio de cinzas encontrado é semelhante a $0,19 \%$ do estudo de TERRAB et al. (2003) e 0,18\% encontrado por MARCHINI et al. (2004).

As cinzas são um parâmetro bastante utilizado nas determinações que visam verificar a qualidade do mel e expressam o conteúdo de minerais presentes nele (MARCHINI et al., 2005). As diferenças no conteúdo mineral do mel estão relacionadas ao tipo de solo no qual a planta, que é fonte de néctar, está localizada (LACHMAN et al., 2007).
Os valores de sólidos insolúveis (Tabela 1) estavam abaixo de $1 \mathrm{~g} \mathrm{~kg}^{-1}$, que é especificado pela legislação brasileira (BRASIL, 2000), o que também qualifica os méis analisados. Esses valores encontrados foram inferiores ao valor médio de $0,8 \mathrm{~g}$ $\mathrm{kg}^{-1}$ encontrado por SILVA et al. (2004), que analisaram méis do Piaú e o intervalo de variação se mostrou semelhante ao observado por EVANGELISTARODRIGUES et al. (2005), que foi de 0,013 a 0,192g $\mathrm{kg}^{-1}$ em amostras de méis da Paraíba.

Observou-se que não houve diferença significativa no $\mathrm{pH}$, nos açúcares redutores e nãoredutores, nas cinzas e nos sólidos insolúveis nas amostras de mel dos mesmos apicultores nas floradas de dois anos consecutivos. Verificou-se que mesmo os méis sendo produzidos na mesma região houve diferença significativa na umidade, acidez e HMF.

As diferenças significativas observadas nos méis para umidade e HMF ocorreram provavelmente devido a variações nas condições climáticas durante o período de produção e beneficiamento do mel em ambos os períodos analisados. Já as diferenças na acidez referem-se à quantidade dos ácidos orgânicos que varia de acordo com as diferentes fontes de néctar (NANDA et al., 2003).

\section{CONCLUSÕES}

Os méis provenientes da região noroeste do Estado do Rio Grande do Sul apresentam boa qualidade e características físico-químicas compatíveis ao Regulamento de Identidade e Qualidade do Mel do Ministério da Agricultura. Observou-se que não houve diferença significativa no $\mathrm{pH}$, nos açúcares redutores e não-redutores, nas cinzas e nos sólidos insolúveis nas amostras de mel dos mesmos apicultores nas floradas de dois anos consecutivos.

\section{AGRADECIMENTOS}

Os autores agradecem à Associação dos Apicultores de Santa Rosa-RS, pelas amostras de méis cedidas durante a Feira do Mel - Edições de 2005 e 2006.

\section{REFERÊNCIAS}

AOAC-Association of Official Analytical Chemists. Official methods of analysis. 16.ed. rev.4. Washington, 1998. 1170p.

AZEREDO, L.C. et al. Protein contents and physicochemical properties in Money simples of Apis mellifera of different origins. Food Chemistry, London, v.80, p.249-254, 2003.

BRASIL. Ministério da Agricultura Pecuária e Abastecimento. Instrução Normativa 11, de 20 de outubro de 2000, Regulamento técnico de identidade e qualidade do mel.

Ciência Rural, v.38, n.6, set, 2008. 
Diário Oficial, Brasília, 20 de outubro de 2000, Seção 001, p.16-17.

CAC-Codex Alimentarius Commission. Official methods of analysis. Rome, 1990. V.3, supl.2, p.15-39.

CORBELLA, E.; COZZOLINO, D. Classification of the floral origin of Uruguayan honeys by chemical and physical characteristics combined with chemometrics. Food Science and Technology, London, v.39, n.5, p.534-539, 2006.

EVANGELISTA-RODRIGUES, A. et al. Análise físico-química dos méis das abelhas Apis mellifera e Melipona scutellaris produzidos em regiões distintas no Estado da Paraíba. Ciência Rural, Santa Maria, v.35, n.5, p.1166-1171, 2005.

GLEITER, R.A. et al. Influence of type and state of crystallization on the water activity of honey. Food Chemistry, London, v.96, n.3, p.441-445, 2006.

INSTITUTO ADOLFO LUTZ. Normas analíticas do Instituto Adolfo Lutz. 3.ed. São Paulo, 1985. V.1, p.27.

LACHMAN, J. et al. Analysis of minority honey components: Possible use for the evaluation of honey quality. Food Chemistry, London, v.101, n.3, p.973-979, 2007.

MARCHINI, L.C. et al. Composição físico-química de amostras de méis de Apis mellifera L. do Estado do Tocantins, Brasil. Boletim da Indústria Animal, Nova Odessa, v. 61, n.2, p.121134, 2004.

MARCHINI, L.C. et al. Análise de agrupamento, com base na composição físico-química, de amostras de méis produzidos por
Apis mellifera L. no Estado de São Paulo. Ciência e Tecnologia de Alimentos, Campinas, v.25, n.1, p.8-17, 2005

NANDA, V. et al. Physico-chemical properties and estimation of mineral content in honey produced from different plants in Northern India. Journal of Food Composition and Analysis, San Diego, v.16, p.613-619, 2003.

PÉREZ, R.A. et al. Amino acid composition and antioxidant capacity of Spanish honeys. Journal of Agricultural and Food Chemistry, Easton, v.55, n.2, p.360-365, 2007.

SERRANO, S. et al. Chemical and physical parameters of Andalusian honey: classification of Citrus and Eucalyptus honeys by discriminant analysis. Food Chemistry, London, v.87, n.4, p.619-625, 2004.

SILVA, C.L. et al. Caracterização físico-química de méis produzidos no Estado do Piauí para diferentes floradas. Revista Brasileira de Engenharia Agrícola e Ambiental, Campina Grande, v.8, n.2-3, p.260-265, 2004

TERRAB, A. et al. Characterization of northwest Moroccan honeys by gas chromatographic-mass spectrometric analysis of their sugar components. Journal of the Science of Food and Agriculture, London, v.82, p.179-185, 2001.

TERRAB, A. et al. Palynological physicochemical and colour characterization of Moroccan honeys. II. Orange (Citrus sp.) honey. International Journal of Food Science and Technology, Oxford, v.38, p.387-394, 2003.

TERRAB, A. et al. Characterization of Spanish thyme honeys by their physicochemical characteristics and mineral contents. Food Chemistry, London, v.88, n.4, p.537-542, 2004. 